\title{
Counseling and Blood Pressure Examination Activities in the Coastal Community of Talia, Kendari City as an Effort to Detect Hypertension from an Early Age
}

\section{Kegiatan Penyuluhan dan Pemeriksaan Tekanan Darah Pada Masyarakat Pesisir Talia Kota Kendari Sebagai Upaya Deteksi Dini Hipertensi}

\author{
Irma Yunawati, ${ }^{\mathrm{a},{ }^{*},}$, Siti Rabbani Karimuna ${ }^{\mathrm{b}}$, L. Lisnawaty $^{\mathrm{a}}$, \& J. Jafriati ${ }^{\mathrm{b}}$ \\ ${ }^{a}$ Program Studi Gizi, Universitas Halu Oleo, Kendari, Sulawesi Tenggara, 93232, Indonesia \\ ${ }^{b}$ Program Studi Kesehatan Masyarakat, Universitas Halu Oleo, Kendari, Sulawesi Tenggara, 93232, Indonesia
}

\begin{abstract}
Hypertension is a disease that is often found in primary health care. Hypertension can increase the risk of cardiovascular disease. One way to prevent hypertension can be done through providing health education, particularly for people who are at risk of developing hypertension. This community service aimed to carry out early detection and increase the knowledge and awareness of the Talia coastal community about hypertension. This community service was carried out in April 2019 with the target of the Talia coastal community. The community service team came from the Faculty of Public Health, Halu Oleo University, which has expertise in the fields of nutrition and public health. This activity consisted of several stages, including the preparation stage which included community surveys, administrative and licensing arrangements, preparation of extension media in the form of leaflets and lecture materials, as well as preparing the tools used for blood pressure examinations, while the implementation stage included counseling in the form of lectures and leaflet distribution on hypertension and blood pressure examinations to the target community. Based on the results of observation, this activity was qualitatively considered successful even though it was still not optimal. Indicators of success can be shown through the ease of licensing and assistance from the Head of Talia Village, the target community who obtained knowledge about early prevention and proper control of hypertension, the community who found out their respective blood pressure, so they can be more aware of the importance of a healthy and balanced life and will regularly to check their blood pressure, and always actively participate until the end of the event.
\end{abstract}

\begin{abstract}
Abstrak
\footnotetext{
* Corresponding author:

E-mail address: irmayunawati@uho.ac.id (Irma Yunawati)
}

Hipertensi merupakan penyakit yang sering ditemukan pada pelayanan kesehatan primer. Hipertensi dapat meningkatkan risiko terjadinya penyakit kardiovaskular. Salah satu cara pencegahan hipertensi yaitu melalui pendidikan kesehatan terutama pada masyarakat berisiko. Tujuan pengabdian masyarakat ini yaitu melakukan deteksi dini serta meningkatkan pengetahuan dan kesadaran masyarakat pesisir Talia tentang hipertensi. Pengabdian masyarakat ini dilakukan pada bulan April 2019 dengan sasaran masyarakat pesisir Talia. Tim pengabdian berasal dari Fakultas Kesehatan Masyarakat Universitas Halu Oleo yang memiliki kepakaran di bidang gizi dan kesehatan masyarakat. Kegiatan ini terdiri dari tahap persiapan meliputi survey masyarakat,

Mattawang: Jurnal Pengabdian Masyarakat is licensed under an

Attribution-NonCommercial-ShareAlike 4.0 International (CC BY-NC-SA 4.0) 
pengurusan administrasi dan perizinan, penyusunan media penyuluhan dalam bentuk leaflet dan materi ceramah, serta persiapan alat yang digunakan untuk pemeriksaan tekanan darah, sedangkan tahap pelaksanaan meliputi penyuluhan dalam bentuk ceramah dan pembagian leaflet tentang hipertensi serta pemeriksaan tekanan darah kepada masyarakat sasaran. Berdasarkan pengamatan, secara kualitatif kegiatan ini dapat dikatakan berhasil meski belum maksimal. Indikator keberhasilan dapat ditunjukkan melalui kemudahan perizinan dan bantuan dari Lurah Talia, masyarakat sasaran mendapatkan pengetahuan tentang upaya pencegahan dini dan pengendalian yang tepat terhadap hipertensi, masyarakat sasaran mengetahui tekanan darah masing-masing, sehingga ke depannya dapat lebih menyadari pentingnya hidup sehat bergizi seimbang dan rutin memeriksakan tekanan darah, serta keterlibatan peserta secara aktif sampai akhir acara.

(C) 2020Author(s).

Kata kunci : Counseling; Blood Pressure Examination; Coastal Communities; Hypertension.

\section{Pendahuluan}

Hipertensi adalah salah satu masalah kesehatan yang banyak dialami oleh masyarakat Indonesia. Hipertensi merupakan kondisi yang sering ditemukan pada pelayanan kesehatan primer (Kementerian Kesehatan Republik Indonesia, 2014). Prevalensi hipertensi di Indonesia berdasarkan pengukuran tekanan darah menunjukkan penurunan dari 29,8\% tahun 2007 menjadi 25,8\% tahun 2013 dan meningkat menjadi 34,11\% tahun 2018 (Departemen Kesehatan Republik Indonesia, 2008; Kementerian Kesehatan Republik Indonesia, 2013; Kementerian Kesehatan Republik Indonesia, 2018). Di Sulawesi Tenggara, prevalensi hipertensi berdasarkan pengukuran tekanan darah tahun 2013 yaitu 22,5\%, meningkat menjadi 29,75\% tahun 2018 (Kementerian Kesehatan Republik Indonesia, 2013; Kementerian Kesehatan Republik Indonesia, 2018). Jumlah kejadian hipertensi di masyarakat diperkirakan melebihi angka yang tercatat, mengingat tanda dan gejala hipertensi yang samar dan belum dirasakan oleh penderitanya sampai terjadi komplikasi.

Hipertensi adalah penyakit yang didefinisikan sebagai peningkatan tekanan darah secara menetap (Dipiro, et al., 2011). Hipertensi atau tekanan darah tinggi adalah peningkatan tekanan darah sistolik > $140 \mathrm{mmHg}$ dan tekanan darah diastolik > $90 \mathrm{mmHg}$ pada dua kali pengukuran dengan selang waktu lima menit dalam keadaan cukup istirahat/tenang. Hipertensi dibedakan menjadi dua macam, yakni hipertensi primer (esensial) dan hipertensi sekunder (non esensial) (Kementerian Kesehatan Republik Indonesia, 2014). Hipertensi dipicu oleh beberapa faktor risiko, seperti faktor genetik, obesitas, kelebihan asupan natrium, dislipidemia, kurangnya aktivitas fisik, dan defisiensi vitamin D (Dharmeizar, 2012).

Penyakit hipertensi disebut juga sebagai "silent killer" karena tidak menimbulkan tanda dan gejala yang jelas, kecuali sudah masuk ke dalam fase komplikasi. Gejala hipertensi dapat bervariasi pada masing-masing individu dan hampir sama dengan gejala penyakit lainnya. Gejala-gejalanya adalah sakit kepala/rasa berat di tengkuk, mumet (vertigo), jantung berdebar-debar, mudah lelah, penglihatan kabur, telinga berdenging (tinnitus), dan mimisan (Kementerian Kesehatan Republik Indonesia, 2014).

Penyakit hipertensi dapat meningkatkan risiko terjadinya penyakit kardiovaskular. Setiap peningkatan $20 \mathrm{mmHg}$ tekanan darah sistolik atau $10 \mathrm{mmHg}$ tekanan darah diastolik dapat meningkatkan risiko kematian akibat penyakit jantung iskemik dan stroke (Chobanian, et.al., 2003). Terkontrolnya tekanan darah sistolik dapat menurunkan risiko kematian, penyakit kardiovaskular, stroke, dan gagal jantung. Menjalankan pola hidup sehat setidaknya selama $4-6$ bulan terbukti dapat menurunkan tekanan darah dan secara umum dapat menurunkan risiko permasalahan kardiovaskular. Beberapa pola hidup sehat yang dianjurkan diantaranya penurunan berat badan, mengurangi asupan garam, olahraga, mengurangi konsumsi alkohol, dan berhenti merokok (Dipiro, et.al., 2011; Soenarta, 2015).

Angka hipertensi yang tidak terkontrol jumlahnya semakin meningkat, sehingga upaya deteksi dini dan pencegahannya menjadi penting untuk dilakukan. Hipertensi dapat dikontrol dengan berbagai upaya menjaga gaya 
hidup. Hal ini dapat tercapai jika pengetahuan masyarakat mengenai pencegahan dan perawatan hipertensi baik. Sebagai salah satu solusi untuk menekan kejadian hipertensi dapat dilakukan melalui pendidikan kesehatan kepada masyarakat. Penyampaian informasi dan edukasi kesehatan diharapkan dapat meningkatkan pengetahuan, kesadaran, dan keinginan masyarakat dalam mencegah dan melakukan perawatan di rumah, sehingga kejadian hipertensi dapat dicegah terutama pada masyarakat yang berisiko.

Kelurahan Talia merupakan salah satu wilayah pesisir yang ada di Kota Kendari, dan hipertensi adalah salah satu penyakit dengan prevalensi tertinggi. Kebiasaan masyarakat dalam mengonsumsi garam berlebih, kebiasaan merokok dan mengonsumsi kopi, terutama di kalangan para lelaki diduga menjadi faktor penyebab tingginya kejadian hipertensi. Selain itu, kurangnya pengetahuan masyarakat tentang upaya dini mencegah hipertensi dan tidak rutinnya memeriksakan tekanan darah menjadi faktor masalah. Sehingga kegiatan pengabdian masyarakat ini perlu dilakukan dengan tujuan deteksi dini kejadian hipertensi serta meningkatkan pengetahuan dan kesadaran masyarakat pesisir Talia tentang hipertensi.

\section{Metode}

Kegiatan pengabdian kepada masyarakat ini dilakukan pada bulan April 2019 yang bertempat di Kelurahan Talia, Kecamatan Abeli, Kota Kendari. Sasaran pengabdian adalah masyarakat pesisir Talia, Kota Kendari. Tim pengabdian berasal dari Fakultas Kesehatan Masyarakat Universitas Halu Oleo (FKM UHO) yang memiliki kepakaran di bidang gizi dan kesehatan masyarakat.

Kegiatan ini terdiri dari tahap persiapan dan pelaksanaan kegiatan pengabdian kepada masyarakat. Pada tahap persiapan, dilakukan survey masyarakat, pengurusan administrasi dan perizinan, penyusunan media penyuluhan dalam bentuk leaflet dan materi ceramah yang berisi tentang pengertian dan dampak hipertensi, pencegahan dan pengelolaan hipertensi, dan monitoring tekanan darah, serta persiapan alat yang digunakan untuk pemeriksaan tekanan darah. Pada tahap pelaksanaan dilakukan penyuluhan dalam bentuk ceramah dan pembagian leaflet tentang hipertensi serta pemeriksaan tekanan darah kepada masyarakat sasaran oleh tim pengabdian dari FKM UHO.

\section{Hasil dan Pembahasan}

Berdasarkan pengamatan, secara kualitatif kegiatan ini dapat dikatakan berhasil meski belum maksimal. Indikator keberhasilan dapat ditunjukkan melalui beberapa hal yaitu bantuan dan dukungan secara penuh dari Lurah Talia yang ditunjukkan dengan memberikan kemudahan perizinan pelaksanaan kegiatan, peserta penyuluhan yaitu masyarakat pesisir Talia mendapatkan pengetahuan yang bermanfaat tentang upaya pencegahan dini dan pengendalian yang tepat terhadap hipertensi, para peserta kegiatan dapat mengetahui tekanan darah masing-masing, sehingga ke depannya dapat lebih menyadari pentingnya hidup sehat bergizi seimbang dan rutin memeriksakan tekanan darahnya, keterlibatan peserta secara aktif dalam kegiatan penyuluhan dan pengukuran tekanan darah sebagai upaya deteksi dini hipertensi, serta peserta mengikuti kegiatan penyuluhan dan pemeriksaan tekanan darah sampai pada akhir acara.

Pada tahap pelaksanaan kegiatan diketahui bahwa responden terbanyak berusia $41-50$ tahun sebanyak 7 orang $(41,2 \%)$, responden dengan jenis kelamin perempuan yaitu 14 orang $(82,4 \%)$, dan banyak yang mengalami hipertensi yaitu 9 orang $(52,9 \%)$. Meskipun demikian, jumlahnya tidak terlalu berbeda dengan responden yang tidak mengalami hipertensi. Distribusi usia, jenis kelamin, dan kejadian hipertensi dapat dilihat pada tabel 1.

Usia responden terbanyak yang mengalami hipertensi yaitu terdapat pada interval usia $21-30$ tahun, $31-40$ tahun, $41-50$ tahun, dan $51-60$ tahun yang mana masing-masing sebanyak 2 orang responden $(22,2 \%)$. Selain itu, kejadian hipertensi juga banyak terjadi pada jenis kelamin perempuan dibandingkan laki-laki yaitu sebanyak 8 orang $(88,9 \%)$. Distribusi kejadian hipertensi menurut usia dan jenis kelamin dapat dilihat pada tabel 2. 
Umur mempengaruhi kejadian hipertensi. Kejadian hipertensi berbanding lurus dengan peningkatan umur. Hal ini terjadi karena pembuluh darah arteri kehilangan kelenturan bersamaan dengan bertambahnya umur (Sugiharto,2007). Hipertensi adalah masalah kesehatan dengan prevalensi yang tinggi dan jumlahnya meningkat seiring bertambahnya usia. Hipertensi memiliki banyak risiko kesehatan. Selain risiko kardiovaskular, ada sejumlah risiko tambahan dari hipertensi di kalangan orang dewasa yang lebih tua termasuk demensia, cacat fisik, dan jatuh/patah tulang (Buford, 2016).

Pada kegiatan ini juga, masyarakat sasaran yang banyak mengalami hipertensi berjenis kelamin perempuan. Terdapat hubungan yang signifikan antara faktor jenis kelamin dengan kejadian hipertensi pada lansia. Dimana pada masa paruh baya, kejadian hipertensi lebih tinggi pada wanita ketika mengalami menopause (Kusumawaty, Hidayat, \& Ginanjar, 2016). Kejadian hipertensi meningkat pada perempuan umur menopause yang berisiko tinggi menderita hipertensi, dibandingkan perempuan pramenopause. Hal tersebut menimbulkan dugaan bahwa faktor hormonal dan biokimiawi pada masa menopause berperan penting terhadap kejadian hipertensi. Perubahan hormonal yang berhubungan dengan menopause dapat meningkatkan kadar androgen relatif, mengaktifasi Renin Angiotensin System (RAS), meningkatkan kadar renin, plasma endothelin, sensitivitas garam dan resistensi insulin, aktivitas simpatetik, berat badan, dan akhirnya menyebabkan hipertensi (Indonesian Society of Hypertension, 2015).

Tabel 1. Distribusi responden berdasarkan usia, jenis kelamin dan kejadian hipertensi

\begin{tabular}{lll}
\hline Variabel & Frekuensi & $\%$ \\
\hline Usia & 2 & 11,8 \\
$21-30$ tahun & 3 & 17,6 \\
$31-40$ tahun & 7 & 41,2 \\
$41-50$ tahun & 3 & 17,6 \\
$51-60$ tahun & 2 & 11,8 \\
$61-70$ tahun & & \\
Jenis kelamin & 3 & 17,6 \\
Laki-laki & 14 & 82,4 \\
Perempuan & & \\
Tekanan darah & 9 & 52,9 \\
Hipertensi & 8 & 47,1 \\
Tidak hipertensi & & \\
\hline
\end{tabular}

Tabel 2. Distribusi kejadian hipertensi menurut usia dan jenis kelamin

\begin{tabular}{|c|c|c|c|c|c|c|}
\hline \multirow{2}{*}{ Variabel } & \multicolumn{4}{|c|}{ Tekanan darah } & \multirow{2}{*}{ Total } & \multirow{2}{*}{$\%$} \\
\hline & Hipertensi & $\%$ & Tidak hipertensi & $\%$ & & \\
\hline \multicolumn{7}{|l|}{ Usia } \\
\hline $21-30$ tahun & 2 & 22,2 & 0 & 0 & 2 & 11,8 \\
\hline $31-40$ tahun & 2 & 22,2 & 1 & 12,5 & 3 & 17,6 \\
\hline $41-50$ tahun & 2 & 22,2 & 5 & 62,5 & 7 & 41,2 \\
\hline $51-60$ tahun & 2 & 22,2 & 1 & 12,5 & 3 & 17,6 \\
\hline $61-70$ tahun & 1 & 11,2 & 1 & 12,5 & 2 & 11,8 \\
\hline \multicolumn{7}{|l|}{ Jenis kelamin } \\
\hline Laki-laki & 1 & 11,1 & 2 & 25,0 & 3 & 17,6 \\
\hline Perempuan & 8 & 88,9 & 6 & 75,0 & 14 & 82,4 \\
\hline
\end{tabular}


Keberhasilan kegiatan penyuluhan dan pemeriksaan tekanan darah pada masyarakat pesisir Talia, Kota Kendari tidak terlepas dari beberapa faktor pendukung yang sangat berperan dalam kegiatan. Faktor pendukung tersebut antara lain dukungan dan bantuan yang maksimal dari pihak kelurahan serta adanya kesadaran yang cukup baik dari masyarakat yang hadir. Selain itu, kerjasama tim dalam mempersiapkan seluruh kegiatan secara maksimal.

Secara umum, kegiatan penyuluhan dan pemeriksaan tekanan darah pada masyarakat pesisir Talia, Kota Kendari sudah berhasil meski belum mencapai target maksimal yang telah ditetapkan. Hal yang menjadi faktor pengambat terlaksananya kegiatan ini yaitu musim penghujan yang membuat masyarakat sedikit kesulitan menuju lokasi kegiatan karena faktor tidak memiliki payung atau jas hujan. Selain itu, hujan yang terjadi juga membuat beberapa rumah warga terkena banjir yang membuat mereka berfokus dalam menghadapi banjir tersebut, sehingga tidak semua warga dapat menghadiri kegiatan pengabdian ini.
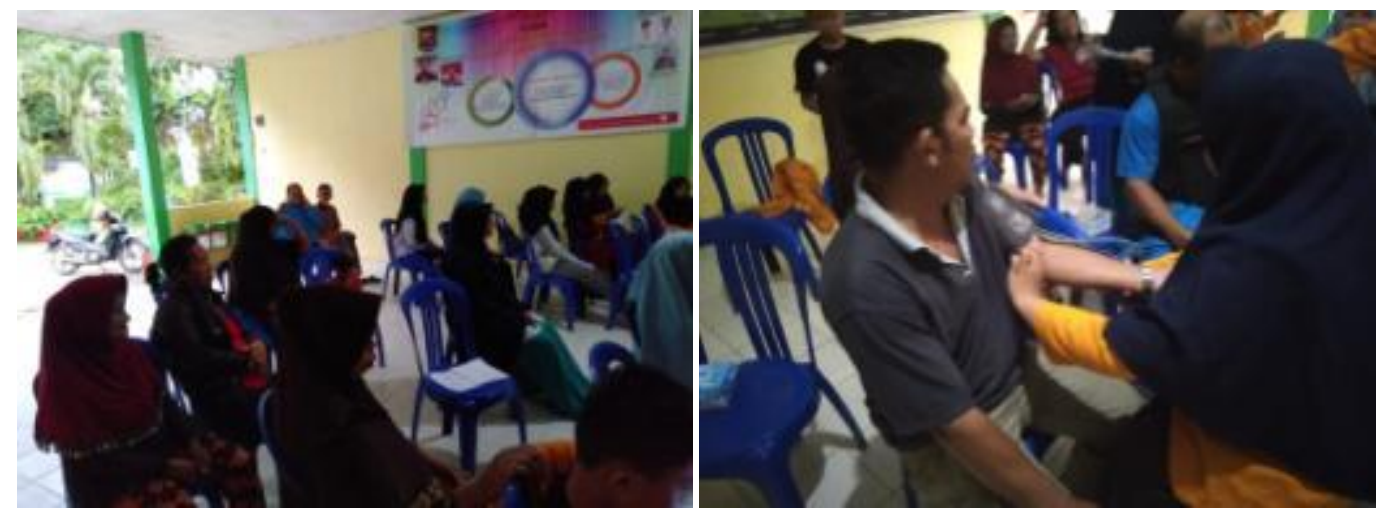

Fig. 1. Kegiatan penyuluhan hipertensi dan pemeriksaan tekanan darah

\section{Kesimpulan}

Pelaksanaan kegiatan pengabdian kepada masyarakat ini berjalan lancar, baik pada tahapan persiapan maupun pelaksanaan kegiatan. Kegiatan pengabdian berupa penyuluhan kesehatan yang dapat meningkatkan pengetahuan tentang upaya pencegahan dan pengendalian masalah hipertensi pada masyarakat pesisir Talia, Kota Kendari, serta pemeriksaan tekanan darah sehingga peserta kegiatan dapat mengetahui tekanan darah masing-masing sebagai upaya deteksi dini hipertensi dan selanjutnya agar masyarakat dapat lebih menyadari pentingnya hidup sehat bergizi seimbang dan rutin memeriksa tekanan darah.

\section{Acknowledgements}

Kami mengucapkan terima kasih kepada Fakultas Kesehatan Masyarakat Universitas Halu Oleo sebagai perguruan tinggi di Sulawesi Tenggara yang telah mendukung pelaksanaan kegiatan pengabdian masyarakat di bidang gizi dan kesehatan. Terima kasih pula kami sampaikan kepada seluruh stake holder, khususnya Lurah Talia dan Camat Abeli serta seluruh masyarakat yang ada di Kelurahan Talia, Kecamatan Abeli, Kota Kendari yang berkontribusi secara langsung maupun tidak langsung dalam kegiatan pengabdian masyarakat ini.

\section{References}

Buford, T. W. (2016). Hypertension and aging. Ageing research reviews, 26, 96-111. 
Chobanian, A. V., Bakris, G. L., Black, H. R., Cushman, W. C., Green, L. A., Izzo Jr, J. L., ... \& Roccella, E. J. (2003). The seventh report of the joint national committee on prevention, detection, evaluation, and treatment of high blood pressure: the JNC 7 report. Jama, 289(19), 2560-2571.

Departemen Kesehatan Republik Indonesia. (2008). Riset Kesehatan Dasar (RISKESDAS) 2007. Jakarta : Badan Penelitian dan Pengembangan Kesehatan, Departemen Kesehatan Republik Indonesia.

Dharmeizar. (2012). Hipertensi. Medicinus: Scientific Journal of Pharmaceutical Development and Medical Application, 25(1), 3-8.

Dipiro, J. T., Talbert, R. L., Yee, G. C., Matzke, G. R., Wells, B. G., \& Posey, L. M. (2011). Pharmacotherapy: A Pathophysiologic Approach, ed. McGraw-Hill Medical, New York.

Indonesian Society of Hypertension. (2015). ABC Hipertensi. Jakarta: Indonesian Society of Hypertension.

Kementerian Kesehatan Republik Indonesia. (2013). Riset Kesehatan Dasar (RISKESDAS) 2013. Jakarta : Badan Penelitian dan Pengembangan Kesehatan, Kementerian Kesehatan Republik Indonesia.

Kementerian Kesehatan Republik Indonesia. (2014). Infodatin Hipertensi. Jakarta : Pusat Data dan Informasi, Kementerian Kesehatan Republik Indonesia.

Kementerian Kesehatan Republik Indonesia. (2018). Laporan Nasional RISKESDAS 2018. Jakarta : Badan Penelitian dan Pengembangan Kesehatan, Kementerian Kesehatan Republik Indonesia.

Kusumawaty, J., Hidayat, N., \& Ginanjar, E. (2016). Hubungan Jenis Kelamin dengan Intensitas Hipertensi pada Lansia di Wilayah Kerja Puskesmas Lakbok Kabupaten Ciamis. Mutiara Medika: Jurnal Kedokteran dan Kesehatan, 16(2), 46-51.

Soenarta, A. A. (2015). Pedoman Tatalaksana Hipertensi Pada Penyakit Kardiovaskuler. Perhimpunan Dokter Spesialis Kardiovaskuler Indonesia (PERKI). $1^{\text {st }}$ Edition. Jakarta : Perhimpunan Dokter Spesialis Kardiovaskular.

Sugiharto, A. (2007). Faktor-faktor risiko hipertensi grade II pada masyarakat (studi kasus di kabupaten Karanganyar) (Doctoral dissertation, program Pascasarjana Universitas Diponegoro). 